OPEN ACCESS

Edited by:

Alexandra Kautzky-Willer,

Medical University of Vienna, Austria

Reviewed by:

Eisuke Amiya,

The University of Tokyo Hospital,

Japan

Leonardo Roever

Federal University of Uberlandia, Brazil

*Correspondence:

Valeria Raparelli

valeria.raparelli@uniroma1.it;

valeria.raparelli@mcgill.ca

${ }^{+}$Listed in Appendix

Specialty section: This article was submitted to

Diabetes,

a section of the journal

Frontiers in Endocrinology

Received: 18 October 2018

Accepted: 05 February 2019

Published: 25 February 2019

Citation:

Raparelli V, Proietti M, Romiti GF,

Lenzi A, Basili S and the EVA

Collaborative Group (2019) The

Sex-Specific Detrimental Effect of Diabetes and Gender-Related Factors

on Pre-admission Medication

Adherence Among Patients

Hospitalized for Ischemic Heart

Disease: Insights From EVA Study.

Front. Endocrinol. 10:107.

doi: $10.3389 /$ fendo.2019.00107

\section{The Sex-Specific Detrimental Effect of Diabetes and Gender-Related Factors on Pre-admission Medication Adherence Among Patients Hospitalized for Ischemic Heart Disease: Insights From EVA Study}

\author{
Valeria Raparelli ${ }^{1,2 \star}$, Marco Proietti ${ }^{3,4}$, Giulio Francesco Romiti ${ }^{3}$, Andrea Lenzi ${ }^{1}$, \\ Stefania Basili ${ }^{3}$ and the EVA Collaborative Group ${ }^{+}$
}

${ }^{1}$ Department of Experimental Medicine, Sapienza University of Rome, Rome, Italy, ${ }^{2}$ Centre for Outcomes Research and Evaluation, Mc Gill University Health Centre Research Institute, Montreal, QC, Canada, ${ }^{3}$ Department of Internal Medicine and Medical Specialties, Sapienza University of Rome, Rome, Italy, ${ }^{4}$ Department of Neuroscience, Istituto di Ricerche Farmacologiche "Mario Negri" IRCCS, Milan, Italy

Background: Sex and gender-related factors have been under-investigated as relevant determinants of health outcomes across non-communicable chronic diseases. Poor medication adherence results in adverse clinical outcomes and sex differences have been reported among patients at high cardiovascular risk, such as diabetics. The effect of diabetes and gender-related factors on medication adherence among women and men at high risk for ischemic heart disease (IHD) has not yet been fully investigated.

Aim: To explore the role of sex, gender-related factors, and diabetes in pre-admission medication adherence among patients hospitalized for IHD.

Materials and Methods: Data were obtained from the Endocrine Vascular disease Approach (EVA) (ClinicalTrials.gov Identifier: NCT02737982), a prospective cohort of patients admitted for IHD. We selected patients with baseline information regarding the presence of diabetes, cardiovascular risk factors, and gender-related variables (i.e., gender identity, gender role, gender relations, institutionalized gender). Our primary outcome was the proportion of pre-admission medication adherence defined through a self-reported questionnaire. We performed a sex-stratified analysis of clinical and gender-related factors associated with pre-admission medication adherence.

Results: Two-hundred eighty patients admitted for IHD (35\% women, mean age 70), were included. Around one-fourth of the patients were low-adherent to therapy before hospitalization, regardless of sex. Low-adherent patients were more likely diabetic (40\%) and employed (40\%). Sex-stratified analysis showed that low-adherent men were more likely to be employed (58 vs. 33\%) and not primary earners (73 vs. 54\%), with more masculine traits of personality, as compared with medium-high adherent men. Interestingly, women reporting medication low-adherence were similar for clinical and gender-related factors to those with mediumhigh adherence, except for diabetes (42 vs. $20 \%, p=0.004$ ). In a multivariate 
adjusted model only employed status was associated with poor medication adherence (OR 0.55, 95\% $\mathrm{Cl}$ 0.31-0.97). However, in the sex-stratified analysis, diabetes was independently associated with medication adherence only in women (OR 0.36; $95 \% \mathrm{Cl}$ 0.13-0.96), whereas a higher masculine BSRI was the only factor associated with medication adherence in men (OR 0.59, 95\% Cl 0.35-0.99).

Conclusion: Pre-admission medication adherence is common in patients hospitalized for $I H D$, regardless of sex. However, patient-related factors such as diabetes, employment, and personality traits are associated with adherence in a sex-specific manner.

Keywords: sex, gender, diabetes, medication adherence, ischemic heart disease, personality traits, employment status

\section{INTRODUCTION}

Poor medication adherence to long-term pharmacological therapies is a public health concern that affects mostly patients with non-communicable chronic diseases $(1,2)$ such as type 2 diabetes mellitus and ischemic heart disease (IHD), both global epidemics of the twenty-first century for men and women (3-5). Among diabetic patients, the non-adherence to glucose-lowering drugs results in a suboptimal glycemic control with higher risk of diabetes-related microvascular complications $(6,7)$. Moreover, diabetic patients should be treated with cardiovascular drugs to prevent macrovascular complications including IHD (8-10). Sex differences in the cardiovascular consequences of diabetes exist and should be specifically addressed in the management of diabetic patients (11-13).

Multiple variables affecting physicians and patients contribute to medication non-adherence, which in turn negatively affects treatment outcomes and causes psychosocial complications, reduces patients' quality of life, and wastes health care resources (14-16). The World Health Organization suggests that improving adherence requires a multidimensional approach (i.e., social and economic factors, health-care team and system-related factors, condition-related factors, therapy-related factors, and patient-related factors), highlighting that psycho-socio-cultural factors need to be considered as contributors (17).

Even though sex- (i.e., biological factors) and gender- (i.e., psycho-socio-cultural factors) differences play a very important role in influencing clinical outcomes, both aspects are generally overlooked and under-reported $(18,19)$. While biological sex variables refer to objectively measurable organs, hormones, genes, anatomy, and physiology, gender represents a social construct that is linked to economic and social status (20). It has several dimensions, including gender identity (how individuals perceive and present themselves), gender norms (behavioral expectations based on individual sex including role in the family, in the workplace, in society, etc.), and gender relations (emotional and economic relations between individuals) (21). As sex and gender are not independent, exclusively assessing one or the other fails to account for identified variations in health $(22,23)$. Specifically, their role and interaction as determinants of medication adherence are still not fully understood. Moreover, the complexity of gender and the lack of a validated standardized measurement, with the exception of the GENESIS-PRAXY gender score $(23,24)$, both contribute to the paucity of data available including medication adherence.

Based on a prospective cohort of patients hospitalized for IHD events, with the unique systematic collection of genderrelated variables, we explored the factors associated with preadmission medication adherence and whether any sex differences exist in the effect of diabetes and gender-related variables on pre-admission medication adherence.

\section{MATERIALS AND METHODS}

Data for the present analysis come from the "Endocrine Vascular disease Approach" (EVA) project (ClinicalTrials.gov Identifier: NCT02737982), an ongoing prospective observational study aiming to explore sex and gender differences in the interaction of platelet function, sex hormone balance, and coronary microvascular dysfunction in IHD (25). In brief, EVA is a registry of men and women, aged 18 and older, who were referred to the cardiac catheterization laboratory to undergo coronary angiography and/or percutaneous coronary intervention for suspected IHD, Patients with active cancer (i.e., currently treated with chemotherapy or at $\leq 5$ years from diagnosis), current pregnancy, previous coronary artery bypass graft, documented moderate-severe valvular heart disease, and prosthetic valve carriers were excluded. Therefore, the EVA study population includes patients with stable coronary artery disease, patients with non-ST elevation acute coronary syndrome and patients with ST elevation myocardial infarction. The recruitment phase is still ongoing.

The study was conducted in full conformance with the principles of the Declaration of Helsinki, the laws and regulations of Italy, or whichever afforded greater protection to the individual. The study obtained the required authorization by the local Ethics Committee of Policlinico Umberto I, Sapienza University of Rome (reference 3786, 24/09/2015). Written informed consent has been obtained from all patients.

Among the study population, we selected baseline data from patients recruited until August 2018. 


\section{Baseline Clinical Characteristics and Gender-Related Factors}

We selected patients with complete information at baseline regarding: (1) anthropometric data (including height, weight, blood pressure, heart rate); (2) independent functional status assessed by the Duke Activity Status Index (26); (3) presence of diabetes; (4) cardiovascular risk factors including family history of cardiovascular disease; hypertension; dyslipidemia; chronic kidney disease; previous cardiovascular events including prior MI and stent implantation. Patients' baseline characteristics were selected from a combination of medical record abstraction and standardized in-person interviews administrated by trained personnel.

According to the definition of gender components designed by the Women's Health Research Network (21), we collected the following gender-related factors: (1) gender role: household's primary earner status and employment status; (2) gender relations: marital status (i.e., married/living with partner vs. others); (3) gender identity: Bem Sex Role Inventory (BSRI) masculine and feminine (27), and level of stress (defined through the 10-item perceived stress scale) (28); (4) institutionalized gender: low socioeconomic status [defined as low education level (i.e., less than secondary school) and/or low household income (i.e., $<1,000$ Euro per month)]. Furthermore, we considered the following as risk-taking behaviors: alcohol consumption (i.e., more than 2 units per day for women and 3 units per day for men), physical inactivity (defined as no recreational activity or less than once per week), and smoking habits (current smoker). All the gender-related variables were collected through selfreported questionnaires.

\section{Pre-admission Medication Adherence Assessment}

Pre-admission medication adherence has been assessed using a self-administrated questionnaire at the baseline visit. A simple self-reported measure of medication adherence, which has been shown to be predictive of blood pressure control (29), was used to measure medication-taking behavior (i.e., trouble in remembering to take medication, spontaneous interruption due to personal judgment) among our hospitalized patients undergoing coronary angiography for suspected IHD. Polypharmacy was defined as more than 5 drugs assumed daily by the patient as previously reported (30). Information concerning the class of drugs taken by the patient include: antithrombotic agents (i.e., anticoagulants and antiplatelet drugs), b-adrenergic receptor blockers (bblockers), hydroxylmethylglutaryl-coenzyme A reductase inhibitors (statins), angiotensin-converting enzyme inhibitors, angiotensin II receptor blockers, oral glucose lowering drugs, or subcutaneous insulin.

\section{Statistical Analysis}

After verification of non-normality, continuous variables were reported as median and interquartile range (IQR). Differences between the groups (low-adherent vs. medium-high adherent) were established, according to non-normal distribution, with a non-parametric test, the Mann-Whitney $U$-test. Categorical variables were reported as counts and percentages, and differences between groups (low-adherent vs. medium-high adherent) were evaluated with chi-square test or Fisher's Exact test when appropriate (cell count $<5$ ).

A logistic regression model was computed to identify the predictors of medium-high adherence. Both in the overall model, as well as in the sex-stratified analysis, variables which significantly differed at baseline with a $p$-value $<0.10$ were identified to be included in a univariate analysis. All variables associated with adherence for $<10 \%(p<0.10)$ at univariate analysis, were included in the final multivariate model. A twosided $p$-value $<0.05$ was considered as statistically significant. All analyses were performed using SPSS v. 25.0 (IBM, NY, USA).

\section{RESULTS}

Among the EVA cohort, 280 (median [IQR] age 70 [63-76] years; $35 \%$ women) patients hospitalized for IHD were analyzed. Preadmission low-adherence was reported in $24 \%(n=67)$ of patients, regardless of sex.

Clinical characteristics according to adherence are reported in Table 1. Low-adherent patients were more likely to be diabetic as compared with adherent patients. No statistically significant difference in pre-admission medication adherence was found between women and men with or without prior history of IHD (74 vs. 77\%, respectively). No differences in age, sex, blood pressure, body mass index, main cardiovascular comorbidities, type of drugs, and polypharmacy were observed between medium-high adherent and low-adherent subjects. The distribution of gender-related factors according to pre-admission medication adherence status is shown in Table 2. The only gender-related factor statistically more prevalent in low-adherent patients was to be employed. Other psycho-socio-cultural factors were similar among the 2 groups.

When data were stratified by sex, we observed that lowadherent men were most likely employed yet not primary earners, and with more masculine personality traits (Table 3). On the other hand, low-adherent women were most likely diabetic and physically inactive, with no statistical differences in any genderrelated factor (Table 4). No differences in the types of drugs taken were observed in both sexes.

Therefore, we explored the determinants of pre-admission adherence: only being employed was independently associated with medication adherence status [Odds Ratio (OR) 0.55, 95\% Confidence Interval (CI) $0.31-0.97, p=0.041$ ] in our cohort (Table 5). However, when we stratified the analysis by sex, only a BSRI masculine (OR 0.59, 95\%CI 0.35-0.99, $p=0.048$ ) was inversely associated with adherence in men, while only diabetes (OR 0.36; 95\%CI 0.13-0.96, $p=0.041$ ) in women (Table 5).

\section{DISCUSSION}

The main findings of our analysis are that: (i) pre-admission poor adherence was highly prevalent, characterizing more than one fourth of men and women hospitalized for IHD; (ii) diabetes 
TABLE 1 | Baseline clinical characteristics of EVA patients according to pre-admission medication adherence.

\begin{tabular}{|c|c|c|c|}
\hline & $\begin{array}{c}\text { Low } \\
\text { adherence } \\
(n=67)\end{array}$ & $\begin{array}{l}\text { Medium-high } \\
\text { adherence } \\
(n=213)\end{array}$ & $p$ \\
\hline $\begin{array}{l}\text { Age, years median } \\
\text { [IQR] }\end{array}$ & 68 [61-78] & 71 [63-76] & 0.447 \\
\hline Women, n (\%) & $24(35.8)$ & $74(34.7)$ & 0.872 \\
\hline $\begin{array}{l}\mathrm{BMI}, \mathrm{kg} / \mathrm{m}^{2} \\
\text { median }[\mathrm{IQR}]\end{array}$ & $\begin{array}{c}27.0 \\
{[24.8-30.0]}\end{array}$ & 26.5 [24.2-29.5] & 0.447 \\
\hline $\begin{array}{l}\text { SBP, } m m H g \\
\text { median [IQR] }\end{array}$ & 130 [120-150] & 130 [120-140] & 0.104 \\
\hline $\begin{array}{l}\mathrm{DBP}, \mathrm{mmHg} \\
\text { median [IQR] }\end{array}$ & 80 [70-85] & 80 [70-80] & 0.537 \\
\hline $\begin{array}{l}\mathrm{HR}, \text { bpm median } \\
{[\mathrm{IQR}]}\end{array}$ & 70 [62-80] & $70[60-76]$ & 0.239 \\
\hline Hypertension & $57(86.4)$ & $181(85.0)$ & 0.781 \\
\hline Dyslipidemia & $41(61.2)$ & $122(57.3)$ & 0.571 \\
\hline Type 2 diabetes & $27(40.3)$ & $58(27.2)$ & 0.042 \\
\hline Active Smoke & $15(22.7)$ & 49 (23.2) & 0.934 \\
\hline Alcohol Abuse & $11(16.4)$ & $36(17.7)$ & 0.805 \\
\hline Physical inactivity & $57(85.1)$ & $167(78.4)$ & 0.234 \\
\hline History of CAD & $28(41.8)$ & $79(37.1)$ & 0.490 \\
\hline Vascular disease & $21(31.8)$ & 58 (27.2) & 0.470 \\
\hline Stroke/TIA & 7 (10.6) & 24 (11.3) & 0.881 \\
\hline CKD & $17(26.2)$ & $53(25.7)$ & 0.945 \\
\hline Polypharmacy & $38(56.7)$ & $106(49.8)$ & 0.321 \\
\hline $\begin{array}{l}\text { DASI, median } \\
{[\mathrm{QQR}]}\end{array}$ & $\begin{array}{c}27.0 \\
{[19.0-42.7]}\end{array}$ & 32.2 [19.0-49.8] & 0.153 \\
\hline \multicolumn{4}{|c|}{ Therapy pre-admission } \\
\hline $\begin{array}{l}\text { - Glucose } \\
\text { lowering drugs }\end{array}$ & $17(25.4)$ & $41(19.2)$ & 0.281 \\
\hline - Insulin & $7(10.4)$ & $12(5.6)$ & 0.172 \\
\hline - Statins & $32(47.8)$ & $110(51.6)$ & 0.579 \\
\hline - Antiplatelets & $43(64.2)$ & $135(63.4)$ & 0.906 \\
\hline - Anticoagulants & $8(11.9)$ & $19(8.9)$ & 0.465 \\
\hline - Beta-Blockers & $30(44.8)$ & $96(45.1)$ & 0.966 \\
\hline - ACEi & $19(28.4)$ & $57(26.8)$ & 0.798 \\
\hline - ARBs & $18(26.9)$ & $76(35.7)$ & 0.183 \\
\hline
\end{tabular}

Data are presented as number of patients (\%) unless otherwise specified. $I Q R$, interquartile range; $B M I$, body mass index; $S B P$, systolic blood pressure; $D B P$, diastolic blood pressure; HR, heart rate; CAD, coronary artery disease; TIA, Transient ischemic attack; CKD, chronic kidney disease; DASI, Duke Activity Status Index; ACEi, Angiotensin converting enzyme inhibitors; ARBs, Angiotensin II receptor blockers. When missing data are more than $10 \%$, they are reported in brackets.

was the only cardiovascular risk factor significantly prevalent in low-adherent patients with IHD before hospitalization; (iii) among the gender-related variables, employed status, as proxy of the gender role, was negatively associated with medication adherence; and (iv) factors related to pre-admission adherence differed between sexes, with diabetes being more relevant for women, while masculine traits of personality were independently associated with low-adherence in men.

Medication low-adherence is a major and costly obstacle in the management of common non-communicable chronic diseases, such as hypertension and diabetes $(16,31,32)$. The
TABLE 2 | Gender-related factors of EVA patients according to pre-admission medication adherence.

\begin{tabular}{lccc}
\hline & $\begin{array}{c}\text { Low } \\
\text { adherence } \\
(\boldsymbol{n}=\mathbf{6 7})\end{array}$ & $\begin{array}{c}\text { Medium-High } \\
\text { Adherence } \\
(\boldsymbol{n}=\mathbf{2 1 3})\end{array}$ & $\boldsymbol{p}$ \\
\hline Employed status & $27(40.3)$ & $57(27.0)$ & 0.039 \\
Primary earner & $19(38.0)$ & $83(49.4)$ & 0.156 \\
Male BSRI, median [IQR] & $5.0[4.1-5.6]$ & $4.7[4.1-5.4]$ & 0.552 \\
Female BSRI, median [IQR] & $5.8[5.2-6.4]$ & $5.9[5.3-6.2]$ & 0.991 \\
High Stress at home & $14(29.2)$ & $44(26.2)$ & 0.682 \\
Married/living with partner & $46(68.7)$ & $149(70.0)$ & 0.840 \\
Low SES* & $36(53.7)$ & $96(45.1)$ & 0.215
\end{tabular}

Data are presented as number of patients (\%) unless otherwise specified.

SES, socioeconomic status; BSRI, Bem Sex Role Inventory; "SES was defined based on low education level and/or personal income. \#data available for 215 patients.

prevalence of medication non-adherence varies tremendously depending on the population studied, the method used for assessment of medication use (e.g., self-report or pharmacy refill data) and the specific medications assessed (15, 33-35). Moreover, significant sex differences were previously reported in general drug-users in terms of intensity of medication use and compliance to treatment (36). Interestingly, in our cohort of patients admitted for an IHD event, the pre-admission poor medication adherence was similarly high (25\%) among women and men. However, we identified different factors associated to inappropriate drug behavior among sexes that should be considered when targeting obstacles for improving patient adherence to pharmacological treatment.

Diabetes is the only condition that reverses the female advantage in cardiovascular risk (37). Diabetic women experience worse clinical outcomes compared to age-matched diabetic men, especially in the setting of ischemic heart disease (38). In our cohort, diabetic women hospitalized for an ischemic coronary event were more likely low-adherent to therapy before admission. Diabetes was found as the only clinical determinant of pre-admission medication adherence in a sex-specific manner, despite the low sample of women enrolled in the present analysis. On the other hand, diabetes loses its explanatory power when gender-related factors are considered in the subgroup of male patients. We provide an example of how controlling and adjusting the analysis for sex can lead to a misinterpretation of data, especially when the women are underrepresented in a study population. Therefore, an analysis disaggregated by sex might inform our better understanding of the outcomes of interest in men and women. In fact, the approach of reporting data disaggregated by sex and a sexstratified analysis are recommended by the international clinical research stakeholders $(39,40)$.

The distinction between sex and gender, which is clear and common in the social sciences, has largely been neglected in health science. In truth, sex and gender are often erroneously used and/or measured interchangeably (18). The integration of sex- and gender-based analysis is a much-needed and, yet, uncommon approach to improving the quality of evidence and guaranteeing the generalizability of findings. However, when 
TABLE 3 | Clinical and gender-related factors in men according to pre-admission medication adherence.

\begin{tabular}{|c|c|c|c|}
\hline & $\begin{array}{c}\text { Low } \\
\text { adherence } \\
(n=43)\end{array}$ & $\begin{array}{l}\text { Medium-high } \\
\text { adherence } \\
(n=139)\end{array}$ & $p$ \\
\hline $\begin{array}{l}\text { Age, years median } \\
{[\mathrm{IQR}]}\end{array}$ & 65 [60-74] & 69 [63-75] & 0.157 \\
\hline $\begin{array}{l}\text { BMl, } \mathrm{kg} / \mathrm{m}^{2} \text { median } \\
\text { [IQR] }\end{array}$ & $\begin{array}{c}27.5 \\
{[25.3-31.0]}\end{array}$ & $27.1[25.1-29.4]$ & 0.576 \\
\hline $\begin{array}{l}\text { SBP, } m m H g \text { median } \\
{[\mathrm{QQR}]}\end{array}$ & 120 [110-130] & 120 [110-130] & 0.200 \\
\hline $\begin{array}{l}\text { DBP, } m m H g \text { median } \\
{[\mathrm{QQR}]}\end{array}$ & 80 [70-85] & 80 [70-85] & 0.973 \\
\hline $\begin{array}{l}\text { HR, bpm median } \\
{[\mathrm{IQR}]}\end{array}$ & 70 [62-78] & 69 [60-76] & 0.279 \\
\hline Hypertension & $37(88.1)$ & $123(88.5)$ & 0.944 \\
\hline Dyslipidemia & $27(62.8)$ & $85(61.2)$ & 0.847 \\
\hline Type 2 diabetes & 17 (39.5) & $43(30.9)$ & $0.2 \mathrm{~s}$ \\
\hline Active Smoke & $13(30.2)$ & $36(26.1)$ & 0.593 \\
\hline Alcohol Abuse & 10 (23.3) & $32(24.2)$ & 0.895 \\
\hline Physical inactivity & $33(76.7)$ & $104(74.8)$ & 0.798 \\
\hline History of CAD & $23(53.5)$ & $61(43.9)$ & 0.270 \\
\hline Vascular disease & $13(31.0)$ & $43(30.9)$ & 0.998 \\
\hline Stroke/TIA & $4(9.5)$ & $14(10.1)$ & 0.917 \\
\hline CKD & $9(22.0)$ & $32(23.7)$ & 0.816 \\
\hline Polypharmacy & $25(58.1)$ & $72(51.8)$ & 0.466 \\
\hline DASI, median [IQR] & 8.5 [3.0-14.0] & $5.0[2.0-11.5]$ & 0.610 \\
\hline Employed status & $25(58.1)$ & $46(33.3)$ & 0.004 \\
\hline Primary earner\# & $18(54.5)$ & 77 (73.3) & 0.042 \\
\hline $\begin{array}{l}\text { Male BSRI, median } \\
\text { [IQR] }\end{array}$ & $5.2[5.0-5.8]$ & $4.9[4.4-5.5]$ & 0.059 \\
\hline $\begin{array}{l}\text { Female BSRI, } \\
\text { median [IQR] }\end{array}$ & $6.0[5.1-6.4]$ & $5.6[5 .-6.2]$ & 0.581 \\
\hline $\begin{array}{l}\text { High stress at } \\
\text { home }\end{array}$ & $5(18.8)$ & 19 (18.4) & 0.969 \\
\hline $\begin{array}{l}\text { Married/living with } \\
\text { partner }\end{array}$ & $33(76.7)$ & 109 (78.4) & 0.817 \\
\hline Low SES* & $20(46.5)$ & $54(38.8)$ & 0.371 \\
\hline
\end{tabular}

Data are presented as number of patients (\%) unless otherwise specified.

$I Q R$, interquartile range; $B M I$, body mass index; SBP, systolic blood pressure; $D B P$, diastolic blood pressure; HR, heart rate; CAD, coronary artery disease; TIA, Transient ischemic attack; CKD, chronic kidney disease; DASI, Duke Activity Status Index; SES socioeconomic status; BSRI, Bem Sex Role Inventory; "SES was defined based on low education level and/or personal income. "data available for 135 men.

considering gender in the evaluation of clinical outcomes, the first hurdle for researchers originates from the apparent lack of standardized methods to measure the complexities of all that gender encompasses. Recently, through a PanCanadian collaboration of a multi-disciplinary team of scientists, a comprehensive list of gender-related variables was established and collected in the setting of premature cardiovascular disease (23). Using the EVA cohort, we could now potentially describe every dimension of gender through a granularity of data which is rarely available. In the analysis adjusted for sex, employment status was the only factor associated to medication adherence: specifically, employed status has a negative influence
TABLE 4 | Clinical and gender-related factors in women according to pre-admission medication adherence.

\begin{tabular}{|c|c|c|c|}
\hline & $\begin{array}{c}\text { Low } \\
\text { adherence } \\
(n=24)\end{array}$ & $\begin{array}{l}\text { Medium-high } \\
\text { adherence } \\
(n=74)\end{array}$ & $p$ \\
\hline $\begin{array}{l}\text { Age, years median } \\
\text { [IQR] }\end{array}$ & 72 [64-81] & 74 [65-78] & 0.568 \\
\hline $\begin{array}{l}\text { BMl, } \mathrm{kg} / \mathrm{m}^{2} \text { median } \\
\text { [IQR] }\end{array}$ & $\begin{array}{c}26.3 \\
{[24.2-28.8]}\end{array}$ & 24.9 [22.2-29.7] & 0.435 \\
\hline $\begin{array}{l}\text { SBP, mmHg median } \\
{[\mathrm{IQR}]}\end{array}$ & $130[125-140]$ & 130 [120-140] & 0.315 \\
\hline $\begin{array}{l}\text { DBP, mmHg median } \\
{[\mathrm{QQR}]}\end{array}$ & 75 [70-90] & 70 [70-80] & 0.259 \\
\hline HR, bpm median [IQR] & 72 [60-80] & 72 [65-77] & 0.526 \\
\hline Hypertension & 20 (83.3) & $58(78.4)$ & 0.601 \\
\hline Dyslipidemia & $14(58.3)$ & $37(50.0)$ & 0.478 \\
\hline Type 2 diabetes, & $10(41.7)$ & 15 (20.3) & 0.037 \\
\hline Active Smoke & $2(8.7)$ & $13(17.8)$ & 0.294 \\
\hline Alcohol Abuse & $1(4.2)$ & $4(5.6)$ & 0.781 \\
\hline Physical inactivity & $24(100.0)$ & $63(85.1)$ & 0.045 \\
\hline History of CAD & $5(20.8)$ & $18(24.3)$ & 0.726 \\
\hline Vascular disease & 8 (33.3) & 15 (20.3) & 0.189 \\
\hline Stroke/TIA & $3(12.5)$ & $10(13.5)$ & 0.899 \\
\hline CKD & 8 (33.3) & $21(29.6)$ & 0.730 \\
\hline Polypharmacy & $13(54.2)$ & 34 (45.9) & 0.484 \\
\hline DASI, median [IQR] & $11[7-25]$ & $10[6.8-15]$ & 0.114 \\
\hline Employed status & $2(8.3)$ & $11(15.1)$ & 0.401 \\
\hline Primary earner & $1(5.9)$ & $6(9.5)$ & 0.637 \\
\hline $\begin{array}{l}\text { Male BSRI, median } \\
{[\mathrm{QQR}]}\end{array}$ & $4.3[3.7-4.6]$ & $4.6[4.0-5.4]$ & 0.106 \\
\hline $\begin{array}{l}\text { Female BSRI, median } \\
{[\mathrm{IQR}]}\end{array}$ & $5.7[5.0-6.8]$ & $6.0[5.6-6.6]$ & 0.773 \\
\hline High stress at home & $8(50.0)$ & 25 (38.5) & 0.400 \\
\hline $\begin{array}{l}\text { Married/living with } \\
\text { partner }\end{array}$ & $13(54.2)$ & $40(54.1)$ & 0.992 \\
\hline Low SES* & $16(66.7)$ & $42(56.8)$ & 0.391 \\
\hline
\end{tabular}

Data are presented as number of patients (\%) unless otherwise specified.

$I Q R$, interquartile range; $B M I$, body mass index; SBP, systolic blood pressure; DBP, diastolic blood pressure; HR, heart rate; $C A D$, coronary artery disease; TIA, Transient ischemic attack; CKD, chronic kidney disease; DASI, Duke Activity Status Index; SES socioeconomic status; BSRI, Bem Sex Role Inventory; "SES was defined based on low education level and/or personal income. "data available for 80 women.

TABLE 5 | Multivariate logistic regression of pre-admission medication adherence in patients admitted for ischemic heart disease.

\begin{tabular}{lccc}
\hline & OR & $\mathbf{9 5 \%} \mathbf{C l}$ & $\boldsymbol{p}$ \\
\hline $\begin{array}{l}\text { OVERALL } \\
\text { Employed status }\end{array}$ & 0.55 & $0.31-0.97$ & 0.041 \\
$\begin{array}{l}\text { MALE PATIENTS } \\
\text { Male BSRI }\end{array}$ & 0.59 & $0.35-0.99$ & 0.048 \\
$\begin{array}{l}\text { FEMALE PATIENTS } \\
\text { Type 2 diabetes }\end{array}$ & 0.36 & $0.13-0.96$ & 0.041 \\
\hline
\end{tabular}

OR, Odds Ratio; Cl, confidence interval; BSRI, Bem Sex Role Inventory.

on adherence to therapy. This difference in adherence between unemployed and employed could be attributed to the busy work schedules of working patients, which could interfere 
with adequate behaviors of self-care. However, in literature, the link between employed status and medication adherence has been barely explored. Our findings have therefore raised important unexplored questions on the mechanisms explaining the association between gender roles and medication adherence in patients at high cardiovascular risk. Apart from work status, personality traits (considered as expressions of gender identity) seem to play a pivotal role in medication adherence $(41,42)$. It was reported that some personality traits such as emotional stability, interpersonal orientation, and motivation in goaldirected behavior are associated to medication adherence in individuals with chronic disease (41). In this light, we observed that beyond clinical characteristics, a higher BSRI masculine score, calculated on personality traits (including risk-taking behavior, independence, competitiveness, strong personality, etc.) can be negatively associated to pre-admission medication adherence in men hospitalized for IHD. This finding may be explained by the tendency of male patients with these personality traits to put high trust in their own ability to manage their health, therefore underestimating the importance of adherence to health providers' prescriptions $(41,43)$.

The present analysis has several strengths worth mentioning. We were uniquely positioned to evaluate all 4 dimensions that gender constructs encompass in a "real-world" contemporary cohort of patients with IHD. We also had a granularity in the data exploring gender constructs which is largely uncommon. Finally, as recommended by international societies and funding agencies $(39,40)$, we could report the data disaggregated by sex.

\section{Limitations}

Some important limitations of the present analysis must be stated. As any observational cohort study, some confounders might not have been assessed and could influence our final multivariate model, as could any missing data points.

Furthermore, the sample size is small, and the EVA study was not specifically designed to test the effect of diabetes on pre-admission medication adherence outcomes. The lack of statistical significance in the effect of sex or gender-related factors may be due to the lack of power to address specific differences. We cannot exclude that, as the sample increases, some relevant differences might emerge. Moreover, the findings refer to a selected cohort of patients at very high cardiovascular risk, hospitalized for an ischemic event, at a single center in Italy, limiting the generalizability of our results. We cannot account for countries with specific differences in psychosocial and cultural factors.

Finally, medication adherence is related to the global patient assumption of drugs pre-admission, yet we cannot describe the nuances of adherence separately for each class of drugs, such as glucose lowering drugs or cardiovascular preventive drugs (i.e., anti-platelets or statins).

\section{Future Directions}

Overall, the present analysis highlights the importance of considering the different effects of clinical characteristics (e.g., diabetes) and gender-related factors (e.g., personality traits or employment status) among women and men, in order to better identify and target high-risk subgroups of patients. The impact of pre-admission medication adherence on clinical outcomes in IHD patients, including diabetics, is a surprisingly underestimated issue (13) which requires further investigation $(44,45)$. Clinicians should consider the use of prior medication adherence as an indicator of future medication-taking behavior.

Future studies-powered and able to apply a gender transformative framework (46) in the consideration of the specific research questions-are warranted, with the overarching aim to ultimately design effective interventions to promote health and well-being.

New approaches such as big data analysis (47) across patient data registries across countries could be interesting avenues to explore the impact of gender-related factors as determinants of clinically relevant outcomes on a larger, population-based scale.

\section{CONCLUSION}

Poor medication adherence is still a highly prevalent condition in patients at high cardiovascular risk. Medication adherence recognizes disease-centered and patient-centered determinants. Among them, gender-related factors (i.e., personality traits and gender role) and diabetes are associated in a sex-specific manner with pre-admission medication adherence of patients hospitalized for IHD. Future clinical trials should test if sex-specific and gender-sensitive interventions might improve medication adherence in high cardiovascular risk conditions, such as women with diabetes.

\section{AUTHOR CONTRIBUTIONS}

VR: study conception and design, coordination of multidisciplinary team research, patients' recruitment, interpretation, and writing manuscript; MP: study design, statistical analysis, data interpretation and writing manuscript; GR: database management, statistical analysis, and writing manuscript; AL: data interpretation, revision of the manuscript; SB: study conception and design, data interpretation, revision of the manuscript; EVA Collaborators: patients recruitment, data entry.

\section{FUNDING}

This study was funded by Scientific Independence of Young Researchers Program (RBSI14HNVT) by the Italian Ministry of Education, University and Research (MIUR) to VR.

\section{ACKNOWLEDGMENTS}

We dedicate this manuscript to Maria Virginia Savoia, may she rest in peace. 


\section{REFERENCES}

1. Munger MA, Van Tassell BW, LaFleur J. Medication nonadherence: an unrecognized cardiovascular risk factor. MedGenMed (2007) 9:58.

2. Lemstra M, Nwankwo C, Bird Y, Moraros J. Primary nonadherence to chronic disease medications: a meta-analysis. Patient Prefer Adher. (2018) 12:721-31. doi: $10.2147 /$ PPA.S161151

3. GBD 2016 Causes of Death Collaborators. Global, regional, and national agesex specific mortality for 264 causes of death, 1980-2016: a systematic analysis for the Global Burden of Disease Study 2016. Lancet (2017) 390:1151-210. doi: 10.1016/S0140-6736(17)32152-9

4. Cho NH, Shaw JE, Karuranga S, Huang Y, da Rocha Fernandes JD, Ohlrogge AW, et al. IDF Diabetes Atlas: global estimates of diabetes prevalence for 2017 and projections for 2045. Diabetes Res Clin Pract. (2018) 138:271-81. doi: 10.1016/j.diabres.2018.02.023

5. Benjamin EJ, Virani SS, Callaway CW, Chamberlain AM, Chang AR, Cheng S, et al. Heart disease and stroke statistics - 2018 update: a report from the American Heart Association. Circulation (2018) 137:E67-492. doi: 10.1161/CIR.0000000000000558

6. Gordon J, McEwan P, Idris I, Evans M, Puelles J. Treatment choice, medication adherence and glycemic efficacy in people with type 2 diabetes: a UK clinical practice database study. BMJ Open Diabetes Res Care (2018) 6:e00512. doi: 10.1136/bmjdrc-2018-000512

7. Larkin AT, Hoffman C, Stevens A, Douglas A, Bloomgarden Z. Determinants of adherence to diabetes treatment. J Diabetes (2015) 7:864-71. doi: 10.1111/1753-0407.12264

8. Harding JL, Pavkov ME, Magliano DJ, Shaw JE, Gregg EW. Global trends in diabetes complications: a review of current evidence. Diabetologia (2018) 62:3-16. doi: 10.1007/s00125-018-4711-2

9. American Diabetes Association. Cardiovascular disease and risk management: standards of medical care in Diabetes 2018. Diabetes Care (2018) 41:S86-104. doi: $10.2337 / \mathrm{dc} 18-\mathrm{S} 009$

10. Kim YY, Lee JS, Kang HJ, Park SM. Effect of medication adherence on long-term all-cause-mortality and hospitalization for cardiovascular disease in 65,067 newly diagnosed type 2 diabetes patients. Sci Rep. (2018) 8:12190. doi: 10.1038/s41598-018-30740-y

11. Regensteiner JG, Golden S, Huebschmann AG, Barrett-Connor E, Chang AY, Chyun D, et al. Sex differences in the cardiovascular consequences of diabetes mellitus: a scientific statement from the american heart association. Circulation (2015) 132:2424-47. doi: 10.1161/CIR.00000000000 00343

12. Raparelli V, Morano S, Franconi F, Lenzi A, Basili S. Sex differences in type-2 diabetes: implications for cardiovascular risk management. Curr Pharm Des. (2017) 23:1471-6. doi: 10.2174/1381612823666170130153704

13. Khunti K, Seidu S, Kunutsor S, Davies M. Association between adherence to pharmacotherapy and outcomes in type 2 diabetes: a meta-analysis. Diabetes Care (2017) 40:1588-96. doi: 10.2337/dc16-1925

14. Osterberg L, Blaschke T. Adherence to Medication. N Engl J Med. (2005) 353:487-97. doi: 10.1056/NEJMra050100

15. Ho PM, Bryson CL, Rumsfeld JS. Medication adherence: its importance in cardiovascular outcomes. Circulation (2009) 119:3028-35. doi: 10.1161/CIRCULATIONAHA.108.768986

16. Brown MT, Bussell JK. Medication adherence: WHO cares? Mayo Clin Proc. (2011) 86:304-14. doi: 10.4065/mcp.2010.0575

17. World Health Organization (WHO). Adherence to Long-Term Therapies: Evidence for Action. (2003) Sec. II:41-52. Available online at: https:// www.who.int/chp/knowledge/publications/adherence_report/en/ (Accessed February 11, 2019).

18. Clayton JA, Tannenbaum C. Reporting sex, gender, or both in clinical research? JAMA (2016) 316:1863-4. doi: 10.1001/jama.2016.16405

19. Legato MJ, Johnson PA, Manson JE. Consideration of sex differences in medicine to improve health care and patient outcomes. JAMA (2016) 316:1865-6. doi: 10.1001/jama.2016.13995

20. Canadian Institutes of Health Research (CIHR). What is Gender? What is Sex? Available online at: http://www.cihr-irsc.gc.ca/e/48642.html. Accessed February 11, 2019.

21. Johnson JL, Greaves L, Repta R. Better Science With Sex and Gender: A Primer for Health Research. Vancouver: Women's Health Research Network (2007).
22. EUGenMed Cardiovascular Clinical Study Group, Regitz-Zagrosek V, OerteltPrigione S, Prescott E, Franconi F, Gerdts E, et al. Gender in cardiovascular diseases: impact on clinical manifestations, management, and outcomes. Eur Heart J. (2016) 37:24-34. doi: 10.1093/eurheartj/ehv598

23. Pelletier R, Ditto B, Pilote L. A composite measure of gender and its association with risk factors in patients with premature acute coronary syndrome. Psychosom Med. (2015) 77:517-26. doi: 10.1097/PSY.0000000000000186

24. Pelletier R, Khan NA, Cox J, Daskalopoulou SS, Eisenberg MJ, Bacon SL, et al. Sex versus gender-related characteristics: which predicts outcome after acute coronary syndrome in the young? J Am Coll Cardiol. (2016) 67:127-35. doi: 10.1016/j.jacc.2015.10.067

25. Raparelli V, Proietti M, Lenzi A, Basili S, Collaborators E. Sex and gender differences in ischemic heart disease: endocrine vascular disease approach (EVA) study design. J Cardiovasc Transl Res. (2018). doi: 10.1007/s12265-018-9846-5. [Epub ahead of print].

26. Hlatky MA, Boineau RE, Higginbotham MB, Lee KL, Mark DB, Califf $\mathrm{RM}$, et al. A brief self-administered questionnaire to determine functional capacity (The Duke Activity Status Index). Am J Cardiol. (1989) 64:651-4. doi: 10.1016/0002-9149(89)90496-7

27. Bem SL. The measurement of psychological androgyny. J Consult Clin Psychol. (1974) 42:155-62.

28. Cohen S, Kamarck T, Mermelstein R. A global measure of perceived stress. J Health Soc Behav. (1983) 24:385. doi: 10.2307/2136404

29. Morisky DE, Green LW, Levine DM. Concurrent and predictive validity of a self-reported measure of medication adherence. Med Care (1986) 24:67-74. doi: 10.1097/00005650-198601000-00007

30. Nobili A, Marengoni A, Tettamanti M, Salerno F, Pasina L, Franchi C, et al. Association between clusters of diseases and polypharmacy in hospitalized elderly patients: results from the REPOSI study. Eur J Intern Med. (2011) 22:597-602. doi: 10.1016/j.ejim.2011.08.029

31. Bosworth HB, Granger BB, Mendys P, Brindis R, Burkholder R, Czajkowski SM, et al. Medication adherence: a call for action. Am Heart J. (2011) 162:412-24. doi: 10.1016/j.ahj.2011.06.007

32. Cutler RL, Fernandez-Llimos F, Frommer M, Benrimoj C, GarciaCardenas V. Economic impact of medication non-adherence by disease groups: a systematic review. BMJ Open (2018) 8:e016982. doi: 10.1136/bmjopen-2017-016982

33. Lam WY, Fresco P. Medication Adherence Measures: An Overview. Biomed Res Int. (2015) 2015:217047. doi: 10.1155/2015/217047

34. Baumgartner PC, Haynes RB, Hersberger KE, Arnet I. A systematic review of medication adherence thresholds dependent of clinical outcomes. Front Pharmacol. (2018) 9:1290. doi: 10.3389/fphar.2018. 01290

35. Kautzky-Willer A, Kamyar MR, Gerhat D, Handisurya A, Stemer G, Hudson $S$, et al. Sex-Specific differences in metabolic control, cardiovascular risk, and interventions in patients with type 2 diabetes mellitus. Gend Med. (2010) 7:571-83. doi: 10.1016/j.genm.2010.12.001

36. Manteuffel M, Williams S, Chen W, Verbrugge RR, Pittman DG, Steinkellner A. Influence of patient sex and gender on medication use, adherence, and prescribing alignment with guidelines. J Womens Health (2014) 23:112-9. doi: 10.1089/jwh.2012.3972

37. Kannel WB, Wilson PWF. Risk factors that attenuate the female coronary disease advantage. Arch Intern Med. (1995) 155:57-61. doi: 10.1001/archinte.1995.00430010063008

38. Hu G, Jousilahti P, Qiao Q, Katoh S, Tuomilehto J. Sex differences in cardiovascular and total mortality among diabetic and non-diabetic individuals with or without history of myocardial infarction. Diabetologia (2005) 48:856-61. doi: 10.1007/s00125-005-1730-6

39. Day S, Mason R, Tannenbaum C, Rochon PA. Essential metrics for assessing sex \& gender integration in health research proposals involving human participants. PLoS ONE (2017) 12:e0182812. doi: 10.1371/journal.pone.0182812

40. Heidari S, Babor TF, De Castro P, Tort S, Curno M. Sex and Gender Equity in Research: rationale for the SAGER guidelines and recommended use. Res Integr Peer Rev. (2016) 1:2. doi: 10.1186/s41073-016-0007-6

41. Axelsson M, Brink E, Lundgren J, Lötvall J. The influence of personality traits on reported adherence to medication in individuals with chronic disease: 
an Epidemiological study in West Sweden. PLoS ONE (2011) 6:e18241. doi: 10.1371/journal.pone.0018241

42. Axelsson M, Emilsson M, Brink E, Lundgren J, Torén K, Lötvall J. Personality, adherence, asthma control and health-related quality of life in young adult asthmatics. Respir Med. (2009) 103:1033-40. doi: 10.1016/j.rmed.2009. 01.013

43. Pagès-Puigdemont $\mathrm{N}$, Mangues MA, Masip $\mathrm{M}$, Gabriele $\mathrm{G}$, Fernández-Maldonado L, Blancafort $\mathrm{S}$, et al. Patients' perspective of medication adherence in chronic conditions: a qualitative study. Adv Ther. (2016) 33:1740-54. doi: 10.1007/s12325-0160394-6

44. Kautzky-Willer A, Harreiter J. Sex and gender differences in therapy of type 2 diabetes. Diabetes Res Clin Pract. (2017) 131:230-41. doi: 10.1016/j.diabres.2017.07.012

45. Kolandaivelu K, Leiden BB, O'Gara PT, Bhatt DL. Non-adherence to cardiovascular medications. Eur Heart J. (2014) 35:3267-76. doi: 10.1093/eurheartj/ehu364
46. Pederson A, Greaves L, Poole N. Gender-transformative health promotion for women: a framework for action. Health Promot Int. (2015) 30:140-50. doi: 10.1093/heapro/dau083

47. Khoury MJ, Ioannidis JPA. Big data meets public health. Science (2014) 346:1054-5. doi: 10.1126/science.aaa2709

Conflict of Interest Statement: The authors declare that the research was conducted in the absence of any commercial or financial relationships that could be construed as a potential conflict of interest.

Copyright $\odot 2019$ Raparelli, Proietti, Romiti, Lenzi, Basili and the EVA Collaborative Group. This is an open-access article distributed under the terms of the Creative Commons Attribution License (CC BY). The use, distribution or reproduction in other forums is permitted, provided the original author(s) and the copyright owner(s) are credited and that the original publication in this journal is cited, in accordance with accepted academic practice. No use, distribution or reproduction is permitted which does not comply with these terms. 


\section{APPENDIX}

EVA Collaborative Group: Claudio Tiberti, Federica Panimolle, Andrea Isidori, Elisa Giannetta, Mary Anna Venneri, Laura Napoleone, Marta Novo, Silvia Quattrino, Simona Ceccarelli, Eleni Anastasiadou, Francesca Megiorni, Cinzia Marchese (Department of Experimental Medicine, Medical Physiopathology, Food Science and Endocrinology Section, Sapienza University of Rome, Rome, Italy); Enrico Mangieri, Gaetano Tanzilli, Nicola Viceconte, Francesco Barillà, Carlo Gaudio, Vincenzo Paravati, Guglielmo Tellan, Evaristo Ettorre, Adriana Servello, Fabio Miraldi, Andrea Moretti, Alessandra Tanzilli, Piergiovanni Mazzonna, Suleyman Al Kindy, Riccardo Iorio, Martina Di Iorio, Gennaro Petriello, Laura Gioffrè, Eleonora Indolfi, Gaetano Pero, Nino Cocco, Loredana Iannetta, Sara Giannuzzi, Emilio Centaro, Sonia Cristina Sergi (Department of Cardiovascular, Respiratory, Nephrologic, Anaesthesiologic and Geriatric Sciences, Sapienza University of Rome, Rome, Italy); Giulio Francesco Romiti, Filippo Toriello, Eleonora Ruscio, Tommaso Todisco, Nicolò Sperduti, Giuseppe Santangelo, Giacomo Visioli, Marco Vano, Marco Borgi, Ludovica Maria Antonini, Silvia Robuffo, Claudia Tucci, Agostino Rossoni, Valeria Spugnardi, Annarita Vernile, Mariateresa Santoliquido, Verdiana Santori, Giulia Tosti, Fabrizio Recchia, Francesco Morricone, Roberto Scacciavillani, Alice Lipari, Andrea Zito, Floriana Testa, Giulia Ricci, Ilaria Vellucci, Marianna Vincenti, Silvia Pietropaolo, Camilla Scala, Nicolò Rubini, Marta Tomassi, Daria Amoroso, Lucia Stefanini, Simona Bartimoccia, Giovanni Talerico, Pasquale Pignatelli, Roberto Cangemi, Salvatore Minisola, Sergio Morelli, Antonio Fraioli, Silvia Nocchi, Mario Fontana (Department of Internal Medicine and Medical Specialties, Sapienza University of Rome, Rome, Italy); Sebastiano Filetti, Massimo Fiorilli (Department of Translational and Precision Medicine, Sapienza University of Rome, Rome, Italy); Danilo Toni, Anne Falcou (Emergency Department Stroke Unit, Sapienza University of Rome, Rome, Italy); Louise Pilote, Tabeth Tsitsi Jiri, Muhammad Ahmer Wali, Amanpreet Kaur, Malik Elharram (McGill University Health Centre Research Institute, Centre for Outcomes Research and Evaluation, Montreal, QC, Canada); Anna Rita Vestri (Department of Public Health and Infectious Disease, Sapienza University of Rome, Roma, Italy); Patrizia Ferroni (San Raffaele Roma Open University and Inter-institutional Multidisciplinary Biobank, IRCCS San Raffaele Pisana, Rome, Italy); Clara Crescioli, Cristina Antinozzi, Francesca Serena Pignataro (Department of Movement, Human and Health Sciences Section of Health Sciences, Unit of Endocrinology, Università degli Studi di Roma "Foro Italico", Rome, Italy); Tiziana Bellini, Alessandro Trentini (Department of Biomedical and Specialty Surgical Sciences, University of Ferrara, Ferrara, Italy); Roberto Carnevale (Department of Medico-Surgical Sciences and Biotechnologies, Sapienza University of Rome, Latina, Italy); Cristina Nocella (Department of AngioCardioNeurology, IRCCS NeuroMed, Pozzilli, Italy); Carlo Catalano, Iacopo Carbone, Nicola Galea (Department of Radiological, Oncological and Pathological Sciences, Sapienza University of Rome, Rome, Italy); Giuliano Bertazzoni, Marianna Suppa, Antonello Rosa, Gioacchino Galardo, Maria Alessandroni, Lorena Cipollone (Department of Emergency Medicine, Policlinico Umberto I, Sapienza University of Rome, Rome, Italy); Alessandro Coppola, Mariangela Palladino (Chest Pain Unit, Policlinico Umberto I, Rome, Italy); Giulio Illuminati, Fabrizio Consorti (Department of Surgical Sciences, Sapienza University of Rome, Rome, Italy); Paola Mariani, Fabrizio Neri, Paolo Salis, Antonio Segatori, Laurent Tellini, Gianluca Costabile (Nursing Team Catheterization Lab Policlinico Umberto I, Rome, Italy). 